\title{
LA PINTORA ANDALUZA MADAME ANSELMA EN FRANCIA: NUEVA APORTACIÓN AL CATÁLOGO DE SU OBRA
}

\author{
THE ANDALUSIAN WOMAN PAINTER MADAME \\ ANSELMA IN FRANCE: A NEW CONTRIBUTION TO \\ THE CATALOGUE OF HER WORK
}

\author{
Magdalena IlLÁn Martín \\ Universidad de Sevilla, España \\ magdaillan@us.es
}

Este artículo aporta el conocimiento de una obra inédita de la pintora gaditana Alejandrina Gessler, quien firmaba sus pinturas con el pseudónimo Madame Anselma. La pintura es una copia de El retrato de Algernon Percy, Décimo Conde de Northumberland, con su esposa y su hija del original de Van Dyck y fue encargada por el Estado francés en 1873 con destino al Musée des Copies de París. La documentación consultada en los Archives Nationales de París nos han permitido localizar la pintura en el Musée de Gap (Departamento de Hautes-Alpes).

Palabras clave: Madame Anselma. Pintura andaluza. Siglo XIX. Archives Nationales, París. Museos franceses.

This article presents an unknown work by the woman painter Alejandrina Gessler, who signed her paintings with the pseudonym Madame Anselma. The painting is a copy of Sir Algernon Percy, 10th Earl of Northuberland, with his first wife and daughter after Van Dyck. It was hired in 1873 by the french Ministère de l'Instruction Publique, des Cultes et des Beaux Arts for the Musée des Copies de Paris and now, it is kept at the Musée de Gap (Hautes-Alpes). Behind it presents an unpublished information about Madame Anselma's career, that it is kept in the Archives Nationales, in Paris.

Key words: Madame Anselma. Andalusian painting. Nineteenth Century. Archives Nationales, Paris. French museums. 


\section{INTRODUCCIÓN ${ }^{1}$}

La artista de origen gaditano Alejandrina Aurora Anselma Gessler y Shaw -cuyo pseudónimo como pintora era Madame Anselma- desarrolló la mayor parte de su trayectoria artística en Francia, en cuya capital residió a partir de 1853 y hasta la fecha de su fallecimiento en $1907^{2}$. En París participó de forma asidua en los Salones desde 1864 a 1885, así como en las exposiciones organizadas por los artistas franceses, como la Exposition des Femmes Peintres et Sculpteurs. Su pintura alcanzó el favor del mercado y de la crítica, que destacaba "su dibujo correcto y valiente; su color brillante y robusto; su modo de hacer amplio y seguro; su composición siempre grandiosa, noble y decorosa, fácil y razonada", valoraciones que resaltaban de forma persistente el hecho de tratarse de una mujer artista y que, en palabras de Bonnat -siguiendo el carácter paternalista habitual entre los críticos al juzgar las obras realizadas por mujeres artistas-, "no pinta como una mujer, pinta como dos hombres" 3 .

${ }^{1}$ Este artículo forma parte de las investigaciones realizadas en el marco del Proyecto del Plan Estatal 2013-2016 Excelencia Pintura Andaluza del Siglo XIX en Francia: Estudio de Fuentes Archivísticas, Hemerográficas y Museológicas. Recuperación y Puesta en Valor (HAR2013-42824-P), financiado por el Ministerio de Economía y Competitividad.

2 Sobre Madame Anselma existen tres exhaustivas fuentes biográficas coetáneas: FULANA DE TAL (pseudónimo de la artista), Recuerdos de Cádiz y Puerto Real (18411850), Librería de Garnier Hermanos, París, 1899; G. M., Biografía artística de Anselma (1861-1905),Librería de Garnier Hermanos, París, 1908; MAYORAL Y PARRACIA, Pedro: Doña Alejandrina Gessler (Madame Anselma Lacroix). Su biografía y sus obras, Imp. Manuel Álvarez, Cádiz, 1908. Cfr. también OSSORIO Y BERNARD, Manuel: Galería biográfica de artistas españoles del siglo XIX, Madrid, Imprenta de Moreno y Rojas, 1883-1884, p. 285; CUENCA, Francisco: Museo de pintores y escultores de Andalucía, La Habana, 1923; BERUETE, Aureliano: Historia de la pintura española en el siglo XIX, Madrid, 1926, p. 133; PÉREZ NEU, Carmen: Galería Universal de Pintoras, Madrid, Editora Nacional, 1964; DIEGO, E. de, La mujer y la pintura del XIX español. Cuatrocientas olvidadas y algunas más, Madrid, Ediciones Cátedra, 2009, pp. 360, 376, 378, 394; PAUKEN, Michel Denise: The life and work of Alejandrina Gessler y Lacroix: a spanish woman artista in nineteenth-century Paris, The University of Texas at Dallas, 2009; TRIVIÑO, Laura: Ellas también pintaban. El sujeto femenino artista en el Cádiz del siglo XIX, Sevilla, Ed. Alfar, 2011; ILLÁN, Magdalena: "Alejandrina Gessler", en Pintoras en España (1859-1926). De María Luisa de la Riva a Maruja Mallo, Universidad de Zaragoza, Zaragoza, 2014, pp. 120-121.

${ }^{3}$ Algunas de las críticas más relevantes sobre la obra de Madame Anselma son: About, Edmond: Salon de 1864, Paris, 1864, p. 260, HELENE B.: "Les femmes au salon de 1866. Le salon d'honneur », Le journal pour toutes, París, 1866, p. 166, JAHYER, Félix: Deuxième étude sur les Beaux-Arts. Salon de 1866, Paris, 1866, p. 16; ABOUT, Edmond: Salon de 1866, Paris, 1867, pp. 284-5 ; y Revue de deux mondes, 1 de junio de 1868, p. 737; FILLONEAU, Ernest: "Salon de 1868, XV", Moniteur des Arts 26 de junio de 1868; Navery, R. de, Le Salon de 1868, Paris, 1868, p. 11; FILLONEAU, Ernest: “Salon de 1870, XIII”, 
El establecimiento de la residencia de Madame Anselma en París no impidió que participara en la escena artística española aceptando encargos, exhibiendo su obra en exposiciones -como en la Exposición Provincial de Bellas Artes de Cádiz, las Exposiciones Nacionales de Bellas Artes o los Salones Hernández-y relacionándose con instituciones culturales como el Ateneo madrileño y la Academia de Bellas Artes de San Fernando de Madrid, donde se conserva un retrato de la artista realizado en 1865 por la pintora francesa y amiga de Alejandrina Gessler, Henriette Browne ${ }^{4}$.

No obstante, fue en París donde Madame Anselma tuvo la mayor demanda de su obra, especialmente a través de los numerosos encargos solicitados por coleccionistas privados y también por la administración pública francesa, con destino a instituciones culturales y religiosas. La obra que damos a conocer es fruto, precisamente, de un encargo dirigido a la pintora por parte del Ministère de l'Instruction Publique, des Cultes et des Beaux Arts francés, con objeto de formar parte de la colección del Musée des Copies creado en 1871. La pintura representa el Retrato de Algernon Percy, décimo Conde de Northumberland, con su esposa y su hija (Figura 1) y reproduce la obra homónima ejecutada por van Dyck hacia 1633-1635.

Como pone de relieve la citada obra, Madame Anselma fue una avezada copista que lograba, según testimonios coetáneos, reproducir de memoria y con extremada fidelidad una pintura tras haberla visto una única vez ${ }^{5}$. No obstante, la artista no limitó su creatividad a la ejecución de copias, sino que desarrolló una dilatada trayectoria profesional en la que trató temas de realismo social, pintura orientalizante y géneros como el retrato, la pintura costumbrista y el desnudo, tema este último que la pintora abordó con éxito de crítica, a pesar de ser un asunto habitualmente censurado a las mujeres artistas: "Temblando quedé hasta conocer la impresión que produciría al público y a los colegas mi atrevimiento

$\overline{\text { Moniteur des Arts, } 17}$ de junio de 1870. Cfr. también SPOELBERCH, Gautier: Charles de, Histoire de Oeuvres de Theophile Gautier avec quatre portraits et deux autographes, II Vol. Slatkine Reprints, Genève, 1968, p. 322. Noticias sobre Madame Anselma en Francia las aporta REYERO, Carlos: París y la crisis de la pintura española 1799-1899. Del Museo del Louvre a la Torre Eiffel, Madrid, Ed. Universidad Autónoma de Madrid, 1993, p. 118.

${ }^{4}$ Sobre este retrato, cfr. p. 27. Sobre la vinculación de la artista con la Academia de San Fernando, cfr. AZCUE BREA, Leticia: "Madame Anselma, pintora gaditana de origen ruso, en la Real Academia de Bellas Artes de San Fernando", Academia, 1985, pp. 259-279.

${ }^{5}$ De memoria ejecutó la copia del Retrato de Lady Caroline Price de Reynolds que contempló en la sección inglesa de la Exposición Universal de 1900. Entre las numerosas copias que realizó destacan las de Murillo (La Sagrada Familia, copiada en dos ocasiones), el Veronés (Sagrada Familia), Tintoretto (El milagro de San Marcos), Andrea del Sarto (Madonna del Saco), Rafael (Santa Cecilia) o Velázquez. 
de haber atacado la pintura del desnudo". En este sentido, su talento propició la ruptura de algunas de las barreras que limitaban el papel de la mujer en la escena artística, siendo nombrada Académica supernumeraria de la Academia de Bellas Artes de Cádiz en 1872 -según recoge el Acta de la sesión: "por estar dentro de las categorías Académicas que reconoce la legislación vigente, estando prohibido que haya Académicas de mérito" ", Académica Honoraria Correspondiente de la Real Academia de Bellas Artes de San Fernando de Madrid en $1891^{8}$ y, en este mismo año, fue la primera mujer admitida como socia honoraria en el Ateneo de Madrid.

\section{MADAME ANSELMA EN FRANCIA}

Madame Anselma (Cádiz, 1831-París, 1907), hija del cónsul general de Rusia en España y consejero de Estado del Zar, Alejandro Gessler, y de Aurora Shaw de Murphy, de origen irlandés, hubo de iniciar su formación artística en Cádiz, aunque se desconoce quiénes pudieron ser sus primeros maestros. Al respecto, el mayor protagonismo que en esta ciudad, de ideas ilustradas y carácter liberal, tuvieron las mujeres en el ámbito del arte -tanto en la Academia de Bellas Artes, como en la Escuela de Artes Aplicadas y Oficios-debió de influir en su decisión de dedicarse a la actividad artística.

Mujer inquieta -de "volcánica cabeza", como la definía D. Ramón Rodríguez, Director de la Academia de Bellas Artes de Cádiz-, culta y cosmopolita, visitó las colecciones artísticas más importantes de Europa y Rusia, configurando igualmente su propia colección. En 1853, con 22 años, contrajo matrimonio con el diplomático francés Charles Lacroix, trasladándose a vivir a París, a la exclusiva Avenue de Messine, 25, cerca del Park Monceau, donde instaló su estudio en la planta superior y estableció sus concurridos salones. Allí desarrolló su formación -en el taller de Charles Chaplin, Gérôme y Lefebvre, junto a pintoras como Mary Cassat o Eva Gonzales- y su madurez artística, alcanzando una exitosa trayectoria profesional, aplaudida por la crítica y demandada por coleccionistas privados y públicos.

Las primeras obras de Madame Anselma están influenciadas por la pintura realista, representando campesinas (Aldeana de Gaussan, 1862) y escenas sociales que describen la vida cotidiana en las aldeas francesas. En esta etapa destaca la obra La adoración de la cruz en Jueves Santo (1869) que fue presentada en el salón

${ }^{6}$ Palabras de la propia artista recogidas en M. C., op. cit., p. 23.

${ }^{7}$ Sobre Madame Anselma en la Academia de Bellas Artes de Cádiz, cfr. BANDA Y VARGAS, Antonio: Catálogo de la Exposición de Académicos de Cádiz (1789-1983), Cádiz, 1983.

${ }^{8}$ La ceremonia de entrega del diploma acreditativo y medalla de académica fue retrasada "porque no habiéndose presentado aún el caso de una admisión de mujer, no se estaba bien al corriente de lo que había que hacer", cfr. M.C. op. cit., p. 46. 
de 1869, y que en 1878 obtuvo la Medalla de Oro en la Exposición Provincial de Bellas Artes de Cádizi ; en esta obra, que representa una escena cotidiana en una iglesia de París, se advierte la influencia de la pintura costumbrista con rasgos procedentes del realismo social.

Tras la Guerra Franco-Prusiana, desde diciembre de 1871 a 1873, Alejandrina Gessler y su familia se trasladaron a España, residiendo en Cádiz y en Madrid. En Cádiz entró en contacto con la pintura costumbrista andaluza y en Madrid volvió al Museo del Prado, relacionándose con Federico de Madrazo. También en estos momentos viajó a Tánger, fruto de cuyo viaje realizó diferentes pinturas de estética orientalizante ${ }^{10}$, destacando La fiesta de natalicio en Tánger (1872-1880) perteneciente a la Real Academia de San Fernando de Madrid. Tras finalizar la guerra, en 1872 regresó a París, reanudando una intensa actividad artística a través de encargos públicos y privados, especialmente de retratos.

Siete años después, en 1885, Madame Anselma presentó en el Salon de París su obra más alabada, una representación de la diosa Juno. La artista muestra a la diosa desnuda, en un ejercicio de virtuosismo plástico y de valentía al abordar un tema, como el desnudo, que resultaba polémico y complicado para las artistas, ya que, por un lado, tenían impedida su presencia en las clases de desnudo del natural y, por otro lado, tenían que luchar contra los prejuicios de la crítica de arte, que observaba entre la censura y la displicencia que una artista tratara este asunto, considerado del ámbito masculino. A pesar de los referidos obstáculos, las críticas fueron favorables: "ejecutada con esa seguridad de los grandes pintores que no raspan nunca. Elegancia, corrección, belleza, color sutilísimo y delicado, bien de dibujo"11. La pintura fue regalada por la artista al Ateneo de Madrid en 1891, institución a la que donó tres obras más - Alegoría de la Poesía y la Música, La Verdad venciendo a la Ignorancia y La Elocuencia abrigando bajo la bandera española a la Paz y las Bellas Artes- que ponen de relieve su sobresaliente capacidad para la ejecución de composiciones complejas en grandes formatos.

A partir de 1890 los problemas de salud de Madame Anselma le obligaron a dedicar amplias temporadas al reposo sin coger los pinceles y a mediados de la década de 1890, el 21 de marzo de 1895, falleció su marido, momento en el cual la artista dejó prácticamente de pintar. Sólo de forma excepcional aceptó algunos encargos y participó en escasas exposiciones, como en la Exposition des Femmes

${ }^{9}$ La artista regaló la pintura a la Academia gaditana, conservándose actualmente en el Museo de Cádiz.

${ }^{10}$ DIZY, Eduardo: Les orientalistes de l'école espagnole, París, Ed. ARC, 1997, p. 120.

${ }^{11}$ PÉREZ NIEVA, Alfonso: "Crónicas madrileñas. Las pintoras y los extranjeros en la Exposición de Bellas Artes”, La Ilustración, Barcelona, 27/07/1890, p. 3. Críticas sobre esta obra: MADRAZO, Pedro de: "Una pintora española", en El Heraldo de Madrid, Madrid, 29/05/1891, p. 1; MADRAZO, Pedro de: "La elocuencia", en La Ilustración española y americana, Madrid, 30/06/1891, p. 6. 
Peintres et Sculpteurs de 1901. Su creatividad derivó hacia la literatura, publicando en 1899 el libro autobiográfico Recuerdos de Cádiz y Puerto Real (18411859), firmado con el pseudónimo Fulana de Tal.

Alejandrina Gessler falleció en París en 1907, editándose un año después dos biografías que ponían en valor su trayectoria personal y artística.

\section{EL RETRATO DE ALGERNON PERCY, DÉCIMO CONDE DE NORTHUMBERLAND, CON SU ESPOSA Y SU HIJA}

E1 20 de febrero 1873 Madame Anselma recibió un encargo formulado desde la Direction des Beaux-Arts del Ministère de l'Instruction Publique, des Cultes et des Beaux Arts francés, para la ejecución de una pintura cuyo destino sería el $M u$ sée des Copies de Francia ${ }^{12}$.

La documentación consultada corrobora, pues, que la pintora formó parte de los artistas seleccionados por el Director de Bellas Artes, Charles Blanc, para su proyecto del Musée des copies - también denominado Musee Européen o Musée Universel-, cuya propuesta fue acogida con personal y vehemente interés por el ministro Jules Simon ${ }^{13}$. Este museo tenía como objetivo exponer reproducciones de las pinturas y esculturas más relevantes de la Historia del Arte conservadas en los museos europeos, sobre todo, italianos, ingleses, rusos y austríacos, y en museos estadounidenses. Para ello, se encomendó a una selección de artistas franceses la ejecución de copias de las obras que consideraran más relevantes, aunque sin especificar ninguna en concreto y dejando al juicio del artista la elección de la obra copiada. Auspiciado con celeridad desde el Ministerio, a pesar de las polémicas que generó, el Musée des Copies inició su breve andadura en 1871, llegando a alcanzar en menos de dos años el número de 157 obras en sus fondos.

Para este Musée des Copies realizó Madame Anselma el Retrato de Algernon Percy, décimo Conde de Northumberland, con su esposa y su hija que reproduce el original de van Dyck ejecutado hacia 1633-1635 y que pertenecía en la década de 1870 a los Marqueses de Salisbury ${ }^{14}$. Para ello, la artista viajó en junio de dicho año a la residencia de los marqueses, en Hatfield House, donde se conservaba la

${ }^{12} \mathrm{~F} / 21 / 464$, Dossier $n^{\circ} 1$, Musées, Gap (Hautes-Apes), 1871-1880, pièce 8.

${ }^{13}$ La idea, a su vez, procedía de Adolphe Thiers, Ministro del Interior en la década de 1830, quien creó en 1834 el Musée des Etudes en la Ecole de Beaux-Arts de París, contando con el apoyo de artistas como Ingres, que ejecutó copias de obras de Rafael con destino a este museo. Sobre el Musée de Copies, cfr. BOIME, A.: "Le Musée des copies", en La Gazette des Beaux-Arts, Octubre, 1964, pp. 237-247. Entre los artistas que participaron en este proyecto figuraba Regnaul, autor de la copia de Las Lanzas de Velázquez.

${ }^{14}$ En la actualidad, la pintura (óleo sobre lienzo, 135 x $180 \mathrm{~cm}$.) se conserva en la colección The National Trust (número de inventario 486239), en su sede de Petworth House and Park (West Sussex, Reino Unido). 
obra y donde estuvo alojada como invitada durante un mes, el tiempo que necesitó para la ejecución de la pintura ${ }^{15}$.

Madame Anselma había revitalizado sus dotes como copista un año antes, en 1872, durante su estancia en Madrid, donde visitó asiduamente el Museo del Prado para copiar dos obras de Velázquez, La rendición de Breda y Las hilanderas, que se conservan actualmente en la Real Academia de Bellas Artes de San Fernando de Madrid ${ }^{16}$. Por ello, acogió con entusiasmo este nuevo encargo de copiar una pintura, ya que enlazaba con el carácter de sus últimas obras.

Como se ha referido anteriormente, el encargo no especificaba la obra que había de copiar la artista, sino que era ésta la que debía elegir la pintura que reproduciría en función de su interés, valoración y devoción ${ }^{17}$. No extraña, en este sentido, que Madame Anselma eligiera el Retrato de Algernon Percy, décimo Conde de Northumberland, con su esposa y su hija de van Dyck, una obra que guarda ciertas concomitancias con La adoración de la cruz, ejecutada en 1869, y con los intereses creativos de la artista en este momento, vinculados a la pintura costumbrista. De hecho, a los ojos de la artista, este retrato no deja de ser una representación de un grupo familiar conformado por Algernon Percy, su primera esposa Lady Anne Cecil y su hija mayor Lady Catherine Percy y, en este sentido, a la pintora hubo de atraerle el innovador tratamiento, intimista y doméstico, que van Dyck otorgó a este retrato.

La pintura de Madame Anselma reproduce fielmente el original en el que se basa, tanto en su formato y tamaño, como en los elementos representados. Se advierte, en este sentido, la minuciosa recreación, por parte de la artista, de la descripción de las ricas indumentarias y de los suntuosos ornamentos que inundan la estancia. Como en sus obras coetáneas -véase la mencionada La adoración de la cruz-, Madame Anselma concede especial protagonismo a la captación de los efectos lumínicos y a la diferenciación de las múltiples texturas de los objetos; para ello, y aunque se advierte que la artista supedita su estilo personal a la estética de la obra copiada, no obstante, recurre a la pincelada suelta y empastada característica de su madurez creativa.

Sin embargo, esta pintura apenas estuvo unos meses colgada en las salas del Musée des Copies, ya que el mismo año en que Madame Anselma ejecutó esta

${ }^{15}$ Cfr. Archives Nationales, F/21/464, Dossier nº1, Musées, Gap (Hautes-Apes), 18711880 , pièce 7.

${ }^{16}$ Las dos obras (La rendición de Breda -81 x 98 cm.- y Las hilanderas -69 x 94 cm.-) fueron alabadas por Federico Madrazo y regaladas por la artista a la Academia madrileña; cfr. PÉREZ SÁNCHEZ, Alfonso E.: Real Academia de Bellas Artes de San Fernando. Inventario de las pinturas, Madrid, 1964, pp. 31 y 42.

${ }^{17}$ En la documentación conservada sobre el proyecto del Musée des Copies se indica: "no es suficiente que las obras se encarguen, sino que despierten la devoción en el artista"; cfr. BOIME, A.: Op. cit., 1964, p. 243. 
pintura, en el mes de diciembre de 1873 y menos dos años después de su inauguración, el museo fue clausurado por el sucesor de Jules Simon en el Ministère de l'Instruction Publique, des Cultes et des Beaux Arts, Chennevières. Con ello, las 157 pinturas y esculturas que conformaban los fondos de este museo se dispersaron y fueron enviadas a diferentes museos e iglesias de la geografía francesa.

Esta pintura de Madame Anselma fue destinada al Musée de Gap, previa solicitud remitida por el Prèfet de Hautes-Alpes para que la Direction de BeauxArts contribuyera a incrementar la colección artística del referido Museo ${ }^{18}$. De tal forma que en 21 de diciembre de 1875 el Retrato de Algernon Percy, décimo Conde de Northumberland, con su esposa y su hija realizado por Madame Anselma ingresó en el Musée de Gap ${ }^{19}$, institución a la que pertenece y donde ha permanecido sin autoría reconocida hasta la actualidad.

Fecha de recepción: 14 de septiembre de 2014

Fecha de aceptación: 28 de noviembre de 2014

${ }^{18}$ La documentación conservada recoge las cartas y las notificaciones oficiales concernientes al proceso de solicitud, concesión, traslado e ingreso de la pintura en el Musée de Gap; cfr. Archives Nationales, F21/4500 (3). F/21/464, Dossier nº ${ }^{\circ}$, Musées, Gap (Hautes-Apes), 1871-1880, pièces 1-6.

${ }_{19}$ Agradezco a Mr. Jean-Louis Mammi, Conseil Général des Hautes-Alpes, Chargé de la Technique, Régisseur des Collections, su colaboración para la realización de este artículo. 


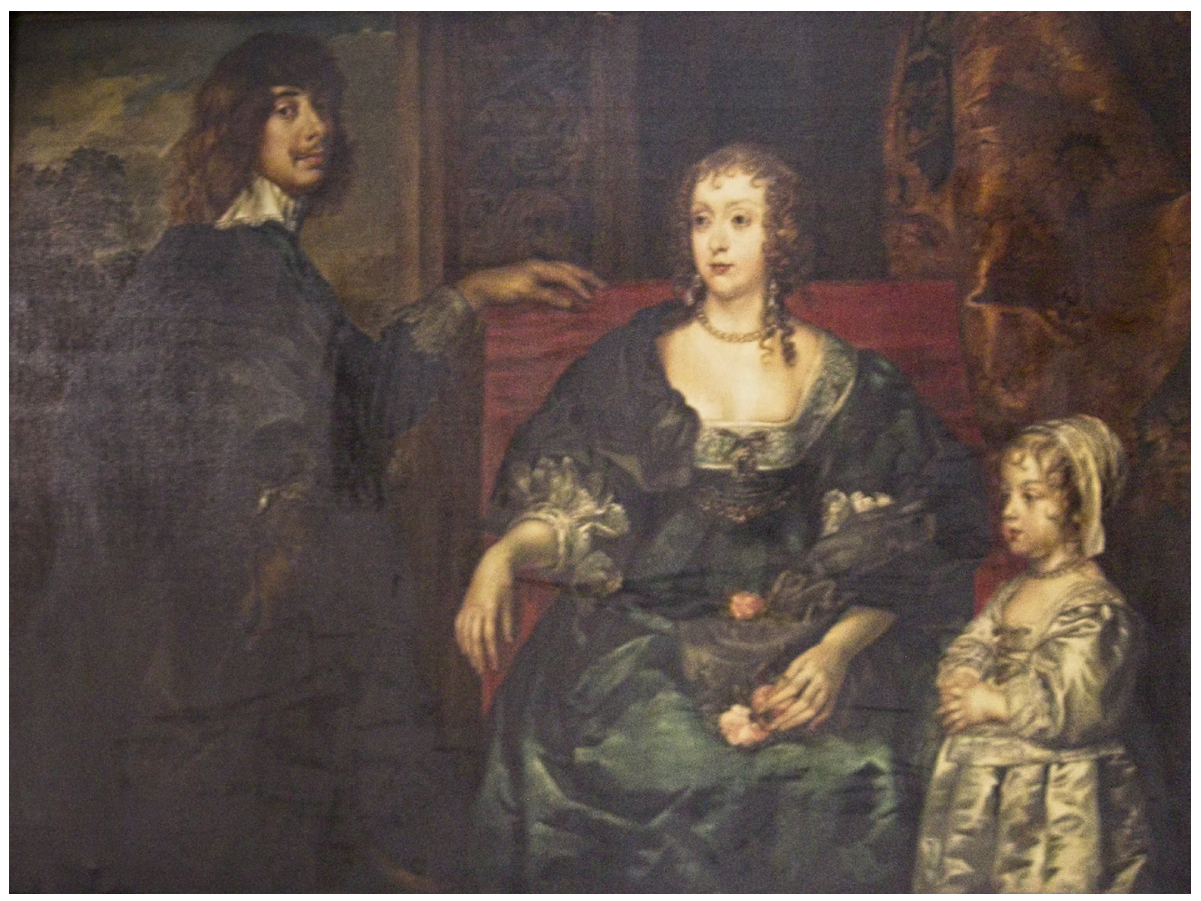

Figura 1. Madame Anselma, Retrato de Algernon Percy, Décimo Conde de Northumberland, con su esposa y su hija, 1873. Musée de Gap, Hautes-Alpes, Francia. 